\title{
INFLUENCE OF VAGINAL ADMINISTRATION OF GLUCOSAMINE HYDROCHLORIDE TO PSYCHO-EMOTIONAL AND LOCOMOTOR ACTIVITY OF SPAY FEMALE RATS
}

\author{
Oksana Sinitsyna \\ Department of Pharmacology \\ National University of Pharmacy \\ 53 Pushkinskaya str., Kharkiv, Ukraine, 61002 \\ ksu.sinitsyna@mail.ru \\ Anna Zaychenko \\ Department of Clinical Pharmacology \\ Institute of Pharmacy Professionals Qualification Improvement \\ 53 Pushkinskaya str., Kharkiv, Ukraine, 61002 \\ zajjchenk.anna@mail.ru \\ Iryna Ryzhenko \\ Department of Pharmacology \\ National University of Pharmacy \\ 53 Pushkinskaya str., Kharkiv, Ukraine, 61002 \\ ir.rizhenko@yandex.ru
}

\begin{abstract}
The significant place in the menopausal syndrome and deficiency of estrogens takes psycho-emotional disorders. Psychosomatic disorders, difficulty of adequate evaluation and correction in menopausal women evidence the fact that this issue is important today. Severe symptoms of menopausal syndrome at violation of psycho-vegetative sphere appear in the early post-menopause, due to final termination of ovarian function and sharply deficiency of estrogens during this period. Intravaginal administration of glucosamine hydrochloride to spay female rats has moderate anti-depressant and anxiolytic effects, accompanied by reduction of the psycho-emotional behavioral reactions, normalization of locomotor activity of animals. As of totality of effects, the estriol reference drug is better than glucosamine hydrochloride. The data reveal prospects of vaginal gel glucosamine hydrochloride in the treatment of menopausal disorders of various origins.

Keywords: glucosamine hydrochloride, vaginal gel, spay female rats, psycho-emotional activity, locomotor activity.

\section{Introduction}

With increase in life expectancy and the proportion of elderly women in the population, the preservation of their life quality has become a pressing medical and social issue of today.

Climacteric is a physiological period, which includes a natural ovarian failure, reduced estrogen level, which in its turn results in development of vasomotor, urogenital, endocrine-metabolic and psycho-emotional disorders. According to researchers, who have studied the clinical manifestations of climacteric in women of 45-54 years, with climacteric syndrome lasting within 5 years, $78.4 \%$ of cases show disorders of psycho-emotional sphere [1-3]. $10 \%$ of women experience depression, which is one of the most severe and difficult-to-treat symptoms, and $13 \%$ - neurotic disorders, showing themselves in tearfulness, irritability, seizures, feeling of fear, anxiety, sleep disorders [4-9].

Pharmacological correction of pathological manifestations of climactericis made withdrugs of estrogens, combined preparations containing estrogens with progestins and phytoestrogens. Hormonal drugs, while having undoubted efficiency, have a number of contraindications, limiting their use [10, 11].

The use of drugs of metabolite-tropic action, which include glucosamine hydrochloride, can be considered as a new approach to prevention and treatment of hypo-estrogenicdisorders. Experimental studies of recent years have shown, that glucosamine hydrochloride, atoral administration to animals, increases synthesis of endogenous estrogen, and has neuroprotective and anxiolytic
\end{abstract}


activity [12]. Researches of vaginal pharmaceutical forms of glucosamine hydrochloride have not been carried out yet.

The goal of this study is the study of glucosamine hydrochloride effect to psycho-emotional and locomotor activity of spay female rats at intravaginal administration.

\section{Materials and Methods}

The researches have been carried out on non-linear white female rats. The experimental animals have been kept in standard vivarium conditions of Central Research Laboratory of the National University of Pharmacy $\left(\mathrm{t}-19-24^{\circ} \mathrm{C}\right.$, humidity less than $50 \%$, natural light mode "daynight"). Rats have been kept on a standard diet, had free access to food and water.

Castration (bilateral spay) of females has been performed under ether anesthesia, aseptically [13]. Sham-operated animals have been subjected to laparotomy and suturing of the wound without removal of ovaries. Vicryl has been used as suture material. The animals have been divided into the following groups: 1 - intact control (IC), 2 - sham-operated females (SOF), 3 - control pathology (CP) - spay animals, 4 - spay rats treated with gel containing $5 \%$ of glucosamine hydrochloride (GH) at a dose of $22.7 \mathrm{mg} / \mathrm{kg}, 5$ - spay rats which received a comparative drug - "Ovestin" vaginal suppositories (active substance - estriol), produced by Organon Company, the Netherlands, series G44874 at a dose of $0.03 \mathrm{mg} / \mathrm{kg}(\mathrm{E}) .6$ animals have been taken out of each group. The drugs under study have been administered vaginally starting with the 35-th day after castration of females, during 28 days. In intact and sham-operated animals, the studied parameters has been determined at the stage of the estrous cycle - diestrus $[14,15]$. Effect of $5 \%$ gel with glucosamine hydrochloride and estriol suppository on locomotor activity, orienting-investigative activities and the emotional sphere of the animalshas been studied with the classical test of "open field". Manifestation of anxiety in animals has been examined in the test of "elevated plus maze", cognitive function has been characterized with help of test of "extrapolation disposal" [16]. Antidepressant properties has been studied with help of test of "behavioral despair" according to Porsolt [17].

The obtained results have been processed using the standard package of STATISTICA 6.0 software. Evaluation of reliability of intergroup differences has been made by parametric $\mathrm{t}-\mathrm{Stu}-$ dent's criterion of at normal distribution of data, angular transformation of Fisher taking into account indicators of an alternative form of reliable interval (p). Differences at $p<0.05$ has been considered statistically significant [18].

Studies were conducted in compliance with the rules of "European Convention for the protection of vertebrate animals used for experimental and scientific purposes"(Strasbourg, 1986) [19].

\section{Results}

Results of the test of "open field" are shown in Table 1.

\section{Table 1}

Effect of intravaginal administration of gel with $5 \%$ glucosamine hydrochloride and suppositories with estriol on indicators of behavioral and emotional reactions in open field test in rats after $\operatorname{spays}(M \pm m), n=6$

\begin{tabular}{cccccc}
\hline Indicators (for 3 min) & IC & SOF & CP & GH 22.7 mg/kg & Estriol 0.03 mg/kg \\
Locomotor activity & \\
\hline Cross the squares & $9,00 \pm 0,52$ & $8,33 \pm 0,56$ & $4,33 \pm 0,49^{* * * *}$ & $7,83 \pm 0,31 * * *$ & $8,50 \pm 0,43 * * *$ \\
\hline \multicolumn{7}{c}{ Tentatively research activities } \\
\hline Mink reflex (holes) & $6,50 \pm 0,85$ & $4,50 \pm 0,72$ & $1,33 \pm 0,33^{* * * *}$ & $4,88 \pm 0,31 * * * * /+$ & $6,50 \pm 0,67 * * * * *$ \\
Vertical columns & $5,00 \pm 0,68$ & $5,83 \pm 0,79$ & $1,17 \pm 0,40^{* * * *}$ & $4,83 \pm 0,60 * * *$ & $5,00 \pm 0,45^{* * *}$ \\
\hline \multicolumn{7}{c}{ Vegetative support emotional reactions } \\
\hline Boluses & $2,86 \pm 0,26$ & $3,17 \pm 0,40$ & $4,33 \pm 0,42^{* * * *}$ & $3,33 \pm 0,33^{+}$ & $2,17 \pm 0,31^{* * * * * *}$ \\
Urinations & $1,50 \pm 0,34$ & $2,17 \pm 0,31$ & $3,17 \pm 0,31^{* * * *}$ & $2,00 \pm 0,26 * * *$ & $2,00 \pm 0,26^{* * *}$
\end{tabular}

Note: Statistically significant differences $(p<0.05)$ : * - with group of IC; ** - with group of SOF; *** - with group of $C P ;+-$ with group of $E$ 
These obtained data suggest that locomotor activity in CP group animals has been significantly reduced: the number of squares crossed decreased 2,1 times in comparison with the intact control.

There was a significant decrease in orienting-exploratory activity of rats, whichresulted in 4,9 times decrease of the number of peeping into the hole and 4,3 times decrease of the number of vertical columns. At this, there has been a change in the emotional state of animals and vegetative support thereof in the form of boluses and urinations increase 1,5 times and 2,1 times respectively.

Intravaginal administration of the gel with $5 \%$ glucosamine hydrochloride has resulted in a significant increase in locomotor activity and indicators of tentatively research activities, as well as in a decrease of symptoms of anxiety in rats against $\mathrm{CP}$ group.

A course of treatment with estriol suppositories has contributed to normalization of the studied parameters, most of which havereached the level of intact controls.

In the test of "extrapolation disposal", the data of sham-operated animals group did not vary from those in the group of intact rats, from statistical statistic point of view (Table 2).

\section{Table 2}

Effect of intravaginal administration of gel with $5 \%$ glucosamine hydrochloride and suppositories estriol on cognitive functions of spay female rats in the test of extrapolation disposal $(M \pm m), n=6$

\begin{tabular}{ccc}
\hline Groups of animals & The solution time, & $\begin{array}{c}\text { \% of the animals, having solved } \\
\text { with the problem }\end{array}$ \\
\hline IC & $100,33 \pm 6,95$ & 100,0 \\
SOF & $125,33 \pm 11,30$ & 83,3 \\
CP & $169,00 \pm 7,72^{* / * *}$ & $33,3^{* * * *}$ \\
Gel GH $22.7 \mathrm{mg} / \mathrm{kg}$ & $162,83 \pm 5,44^{* * * *}$ & $83,3^{* * *}$ \\
E $0.03 \mathrm{mg} / \mathrm{kg}$ & $131,33 \pm 12,98^{* * *}$ & $100,0^{* * *}$
\end{tabular}

Note: Statistically significant differences $(p<0.05): *$ - with a group of intact controls; ** - with shamoperated group of females; *** - with group of control pathology

Animals of CP group, 1,7 times increase of time spent for the solution of the problemhas been noted, and there has been a significant decreasein number of female rats, which have coped with it, by $66,7 \%$ compared to the intact control.

It is shown, that the administration of gel with $5 \%$ glucosamine hydrochloride has notaffected the speed of problem solution by animals, as evidenced by the absence of statistically significant differences with the $\mathrm{CP}$ group of rats. At the same time, the drug resulted in an increase of the number of animals, which have coped with the problem, to $83,3 \%$, even though they have spent more time.

Time spent for solution of the problem, has been significantly decreased by 37.7 compared to a group of CP, against the background of introduction of estriol suppository. At the same time, all the animals have coped with this problem. Under these conditions, the use of this drug has reduced the time spent by rats for the problem solution by 31.5 seconds, compared to the group of animals treated with the gel of glucosamine hydrochloride $5 \%(\mathrm{p}<0.05)$.

Analysis of data in Table 3 shows that the test of "elevated plus-maze" in castrated female rats has resulted in abruptly increased anxiety and decreased locomotor activity, which is shown by a small number of transitions between the branches of the maze. In the group of sham-operated animals, latent period of entrance into a branch sleeve and the number of transitions between the branches have not varied from those in the group of intact controls, from statistical point of view.

At the same time, the time of sham-operated animals staying in dark branches has beensignificantly increased by $40 \mathrm{sec}$. (time spent in bright sleeves has been decreased respectively), which is probably a result of myocardial stress after surgery.

After vaginal administration of gel with $5 \%$ glucosamine hydrochloride to spayed female rats, decrease in symptoms of anxiety was observed as evidenced by the increase in the latent period of entry into the dark labyrinth sleeve, which did not statistically differ from that index in IR 
group. Time spent in bright sleeves did not differ from that in the healthy animals group, but was 30 seconds more than that in sham-operated. The number of transitions between the sleeves differed from that index in all other groups $(\mathrm{p}<0.05)$. Animals, treated with hormone replacement therapy, had locomotor activity improved and anxiety decreased. Data of all four parameters, which were detected in this test, did not statistically differ from the parameters of intact females. It should be noted that the time of staying of those animals in dark sleeves was for 30 seconds less, than that of sham ones and staying in light sleeves was correspondingly longer.

The study of the antidepressant properties of the studied medications by the test of "behavioral despair" according to Porsolt (Table 4), has shown that intact control animals, whose endocrine profilehas not changed, have the lowest total time and the number of immobility acts.

\section{Table 3}

Indicators of behavior in female rats in the test of "elevated plus maze" under the influence of the gel with $5 \%$ glucosamine hydrochloride and suppositories estriol $(\mathrm{M} \pm \mathrm{m}), \mathrm{n}=6$

\begin{tabular}{ccccc}
\hline Groups of animals & $\begin{array}{c}\text { Latent period enter } \\
\text { into dark branch, } \mathbf{s}\end{array}$ & $\begin{array}{c}\text { Duration of stay in } \\
\text { light branch, } \mathbf{s}\end{array}$ & $\begin{array}{c}\text { Duration of stay in } \\
\text { dark branch, } \mathbf{s}\end{array}$ & $\begin{array}{c}\text { Number of } \\
\text { conversions (n) }\end{array}$ \\
\hline IC & $14,00 \pm 2,72$ & $190,83 \pm 4,36$ & $109,17 \pm 4,36$ & $12,33 \pm 0,67$ \\
SOF & $13,50 \pm 2,58$ & $150,83 \pm 10,83 *$ & $149,17 \pm 10,83 *$ & $10,17 \pm 0,54$ \\
CP & $2,83 \pm 0,97 * * *$ & $98,33 \pm 11,08 * * *$ & $201,67 \pm 11,08 * * *$ & $4,17 \pm 0,31 * * *$ \\
Gel GH $22.7 \mathrm{mg} / \mathrm{kg}$ & $0,50 \pm 1,89 * * *$ & $180,00 \pm 4,66 * * * * *$ & $120,00 \pm 4,66 * * * * *$ & $8,17 \pm 0,31 * * * * * * /+$ \\
E $0.03 \mathrm{mg} / \mathrm{kg}$ & $17,00 \pm 3,89 * * *$ & $180,83 \pm 5,69 * * * * *$ & $119,17 \pm 5,69 * * * * *$ & $11,17 \pm 0,60 * * *$
\end{tabular}

Note: Statistically significant differences $(p<0.05)$ : * - with group of IC; ** - with group of SOF; *** - with group of CP; +- with group of $E$

Table 4

Effect of gel with 5\% glucosamine hydrochloride and suppositories with estriol on cognitive function of spay female rats in the test of "behavioral despair according to Porsolt» $(M \pm m), n=6$

\begin{tabular}{ccc}
\hline Groups of animals & Total time of immobilization (t, s) & Number of episodes of immobilization (n) \\
\hline IC & $75,00 \pm 4,08$ & $5,83 \pm 0,31$ \\
SOF & $84,17 \pm 3,01$ & $7,00 \pm 0,52$ \\
CP & $204,17 \pm 9,61 * * *$ & $10,17 \pm 0,70^{* / * *}$ \\
Gel GH $22,7 \mathrm{mg} / \mathrm{kg}$ & $113,33 \pm 2,47 * * * * * * /+$ & $7,00 \pm 0,26^{* * *}$ \\
E $0,03 \mathrm{mg} / \mathrm{kg}$ & $86,67 \pm 5,73^{* * *}$ & $6,83 \pm 0,60^{* * *}$
\end{tabular}

Note: Statistically significant differences $(p<0.05)$ : * - with group of intact controls; ** - with group of sham-operated females; *** - with group of disorders control; + - with group of E

In sham-operated animals these indicators have not statistically varied from those of normal rats. At the same time, for $\mathrm{CP}$ group they have reached a maximum value, 2.7 times higher than value of interact control, asof total time and 1.7 times as of the number of episodes of immobilization.

Introduction of gel with $5 \%$ glucosamine hydrochloride to castrated rats has resulted in significant decrease of total time of immobilization by 90.8 seconds compared to $\mathrm{CP}$, and the number of episodes of immobilization has not varied from the healthy animals. The female rats, treated with suppositories E, has not shown signs of depression, which has been confirmed by the absence of statistically significant differences as of the studied parameters in the intact control.

Thus, the results of the research show that the most pronounced antidepressant effect in female rats at psycho-emotional disorders, caused by the removal of gonads, has been provided 
with E, which has completely reduced their symptoms of depression. Gel with $5 \%$ glucosamine hydrochloride has shown moderate antidepressant properties.

\section{Discussion of the results}

Data of "open field" test suggest that on the background of castration, rats experience development of behavioral disorders in the form of lower locomotor activity and indicators of orienting-research activities. At this, gel with $5 \%$ glucosamine hydrochloride has essentially eliminated behavioral problems, specific to $\mathrm{CP}$ animals group.

However, as of the effect on indices of the "hole exploratory behavior" and vegetative component of emotional reactions manifestations (number of boluses), itwas less effective than the reference drug. Introduction of $\mathrm{E}$ has completely leveled behavioral disorders and vegetative support of emotional reactions in experimental animals. Against the background of castration, the females have had significantly disturbed cognitive functions. Gel with $5 \%$ glucosamine hydrochloride showed a moderate effect in correction of cognitive disorders in animals. At the same time, the comparative drug has had most beneficial effect, as in all animals there has been a decrease in the time spent by rats for the solution of the disposal problem.

The results of test of "elevated plus maze" has shown that experimental animals of CP group sharply have had increased anxiety and decreased locomotor activity. The studied drugs have had almost the same anxiolytic effect, and normalizing indirect effect on locomotor activity in female rats.

Based on data of test of "behavioral despair" it has been found that the most pronounced antidepressant effect at psycho-emotional disorders, caused by the removal of gonads, has been shown by E, which at course treatment could reduce symptoms of depression in castrated female rats. Gel with $5 \%$ glucosamine hydrochloride has mild antidepressant effect, yielding suppositories containing estriol, 1.3 times as of effect on behavioral responses.

\section{Conclusions}

Thus, as of the aggregate of obtained data, glucosamine hydrochloride intravaginal administration to castrated female rats has systemic kinds of actions, showing moderate anxiolytic and antidepressant activities, which opens new possibilities of its use for the treatment of climacteric syndrome and deficiency of estrogens.

\section{References}

[1] Baber, R. J., Templeman, C., Morton, T., Kelly, G. E., West, L. (1999). Randomized placebo-controlled trial of an isoflavone supplement and menopausal symptoms in women. Climacteric, 2 (2), 85-92. doi: 10.3109/13697139909025571

[2] Freeman, E. W., Sammel, M. D., Liu, L., Gracia, C. R., Nelson, D. B., Hollander, L. (2004). Hormones and Menopausal Status as Predictors of Depression in Womenin Transition to Menopause. Archives of General Psychiatry, 61 (1), 62. doi: 10.1001/archpsyc.61.1.62

[3] Green, S. M., Key, B. L., McCabe, R. E. (2015). Cognitive-behavioral, behavioral, and mindfulness-based therapies for menopausal depression: A review. Maturitas, 80 (1), 37-47. doi: 10.1016/j.maturitas.2014.10.004

[4] Ghosh, M., Rodriguez-Garcia, M., Wira, C. R. (2014). The immune system in menopause: Pros and cons of hormone therapy. The Journal of Steroid Biochemistry and Molecular Biology, 142, 171-175. doi: 10.1016/j.jsbmb.2013.09.003

[5] De Kruif, M., Molendijk, M. L., Haffmans, P. M., Spijker, A. T. (2015). Depression during the perimenopause. Tijdschr Psychiatr., 57 (11), 795-804.

[6] Jung, S. J., Shin, A., Kang, D. (2015). Menarche age, menopause age and other reproductive factors in association with post-menopausal onset depression: Results from Health Examinees Study (HEXA). Journal of Affective Disorders, 187, 127-135. doi: 10.1016/j.jad.2015.08.047

[7] Borkoles, E., Reynolds, N., Thompson, D. R., Ski, C. F., Stojanovska, L., Polman, R. C. J. (2015). The role of depressive symptomatology in peri- and post-menopause. Maturitas, 81 (2), 306-310. doi: 10.1016/j.maturitas.2015.03.007 
[8] Soares, C. N. (2010). Can depression be a menopause-associated risk? BMC Medicine, 8 (1), 79. doi: 10.1186/1741-7015-8-79

[9] Gavisova, A. A., Tverdikova, M. A., Balushkina, A. A. (2009). Climacteric syndrome: peculiarities of treatment of psychoemotional disorders. Russian medicinal journal, 17 (20), 1408-1411.

[10] Ovsiannikova, T. V., Makarov, I. O. et. al (2010). Local treatment of peri- and postmenopausal urogenital disorders. Journal Obstet., Gynecol. and Reprod., 4 (3), 25-28.

[11] Podzolkova, N. M., Kuznetsova, I. V., Korennaia, V. V. (2014). Hormone therapy in peri- and post menopause: a guide for doctors. Moscow: GEOTAR-Media, 112.

[12] Grintsova, E. E. (2010). On the mechanism of glucosamine hydrochloride cerebroprotective action. Experimental clinical pharmacology of metabolic correctors, Organoprotection and evidence-based medicine. Vinnitsa, 67-76.

[13] Kirshenblat, Ya. D. (1969). Case study on endocrinology. Moscow, 55-57.

[14] Kabak, Ya. M.; Rozen, V. B. (Ed.) (1974). Research of sexual cycle of rodent females by method of vaginal smears: endocrinology case study. Moscow: Medicine, 154.

[15] Yakovleva, L. V., Zaychenko, G. V., Tsypkun, A. G. et. al (2009). Methodological recommendations. Preclinical study of pharmaceutical drugs for treatment of placental dysfunction, 63 .

[16] Khabriev, R. U.; Khabriev, R. U. (Ed.) (2005). Manual on experimental (preclinical) study of new pharmacological substances. Moscow: OJSC “Medicine” Publishing house, 832.

[17] Porsolt, R. D., Lenegre, A., Elliot, J. M. et. al (1992). Behavioural models of depression. Experimental Approaches to Anxiety and Depression. Chichester New York, 73-85.

[18] Khalafyan, A. A. (2007). STATISTICA 6. Statistical data analysis. Moscow: "Binom-press" LTD, 512.

[19] Gordon, J. L., Rubinow, D. R., Eisenlohr-Moul, T. A., Leserman, J., Girdler, S. S. (2016). Estradiol variability, stressful life events, and the emergence of depressive symptomatology during the menopausal transition. Menopause, 23 (3), 257-266. doi: 10.1097/gme.0000000000000528

[20] Kozhemyakin, Y. M., Khromov, A. S., Filonenko, M. A., Sayfetdynova, G. A. (2002). Scientific and practical advice on keeping laboratory animals and work with them. Kyiv: House "Avicenna", 156. 